\title{
Sequence-Specific, Dynamic Covalent Crosslinking
}

Minfeng Li, Kazuhiro Yamato, Kiran Kumar Singarapu, Thomas Szyperski and Bing Gong*

'Department of Chemistry

Natural Sciences Complex

University at Buffalo, The State University of New York

Buffalo, New York 14260

\section{Supporting Information}




\section{Mass Spectra}

I-1. The ESI spectra of 3 treated with $\mathrm{I}_{2}$ in $\mathrm{CH}_{2} \mathrm{Cl}_{2}$ or in $\mathrm{H}_{2} \mathrm{O}$ containing $10 \%(\mathrm{v} \%) \mathrm{THF}$
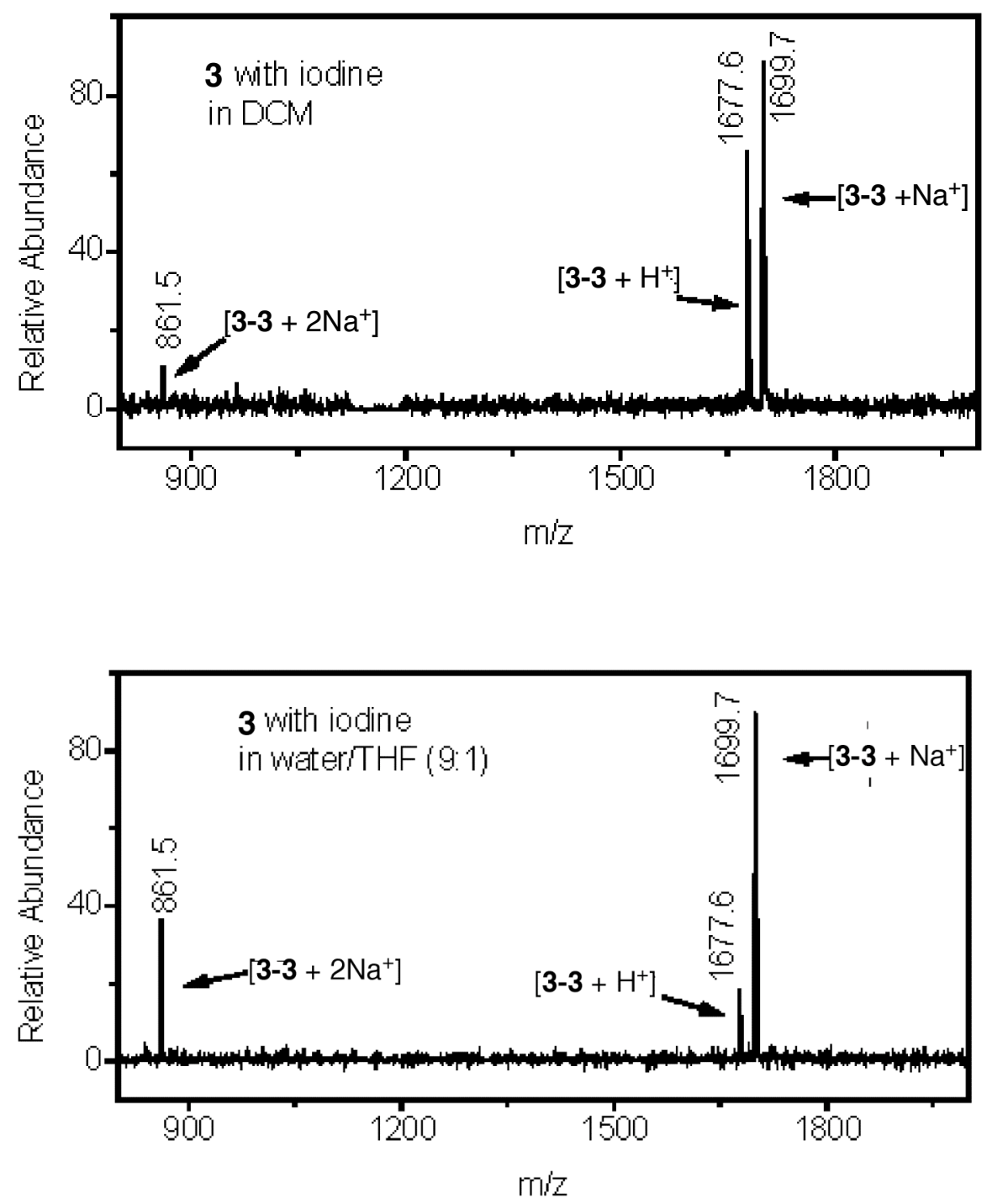
I-2. The ESI spectra of 5 treated with $\mathrm{I}_{2}$ in $\mathrm{CH}_{2} \mathrm{Cl}_{2}$ or in $\mathrm{H}_{2} \mathrm{O}$ containing $10 \%(\mathrm{v} \%)$ THF
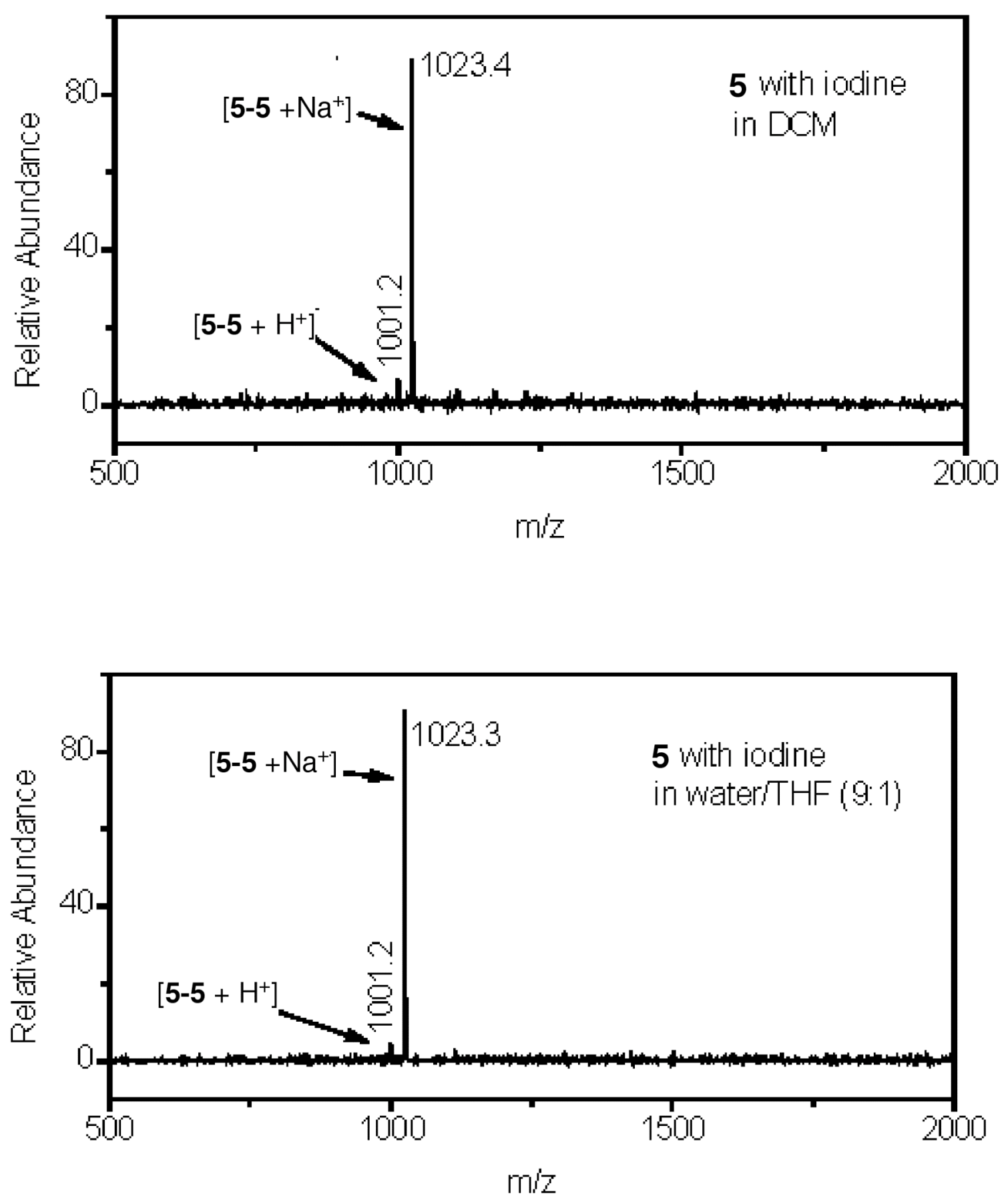


\section{HPLC Traces}

II-1. The HPLC trace of the solution of 3 in $\mathrm{H}_{2} \mathrm{O} / \mathrm{THF}(9 / 1, \mathrm{v} / \mathrm{v})$ in the presence of iodine.

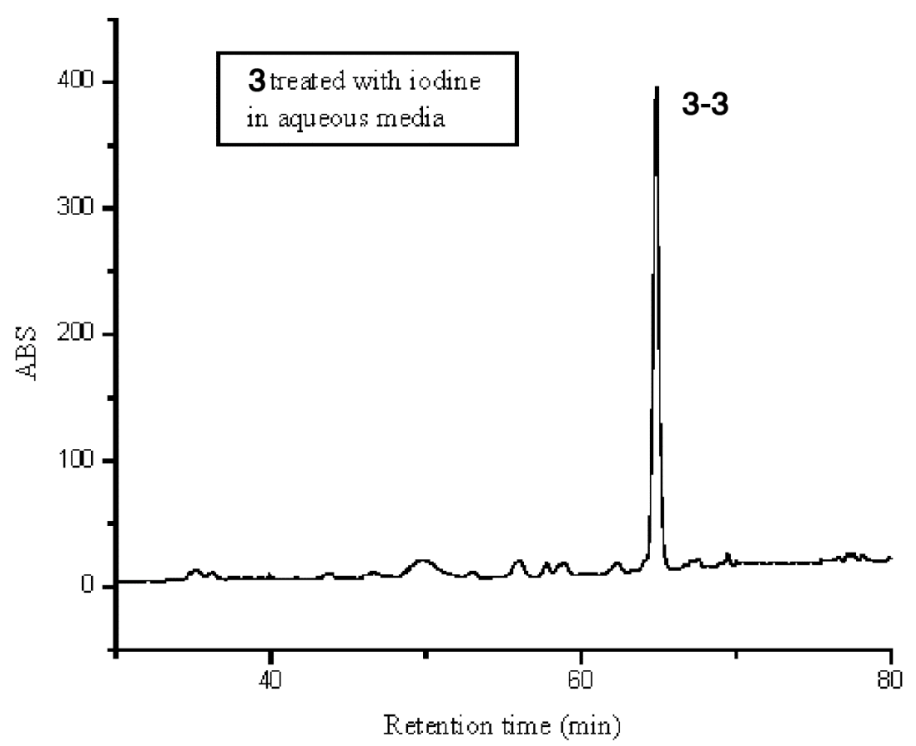

$64.86 \mathrm{~min}$, 3 self-dimer.

II-2. The HPLC trace of the solution of 4 in $\mathrm{H}_{2} \mathrm{O} / \mathrm{THF}(9 / 1, \mathrm{v} / \mathrm{v})$ in the presence of iodine.

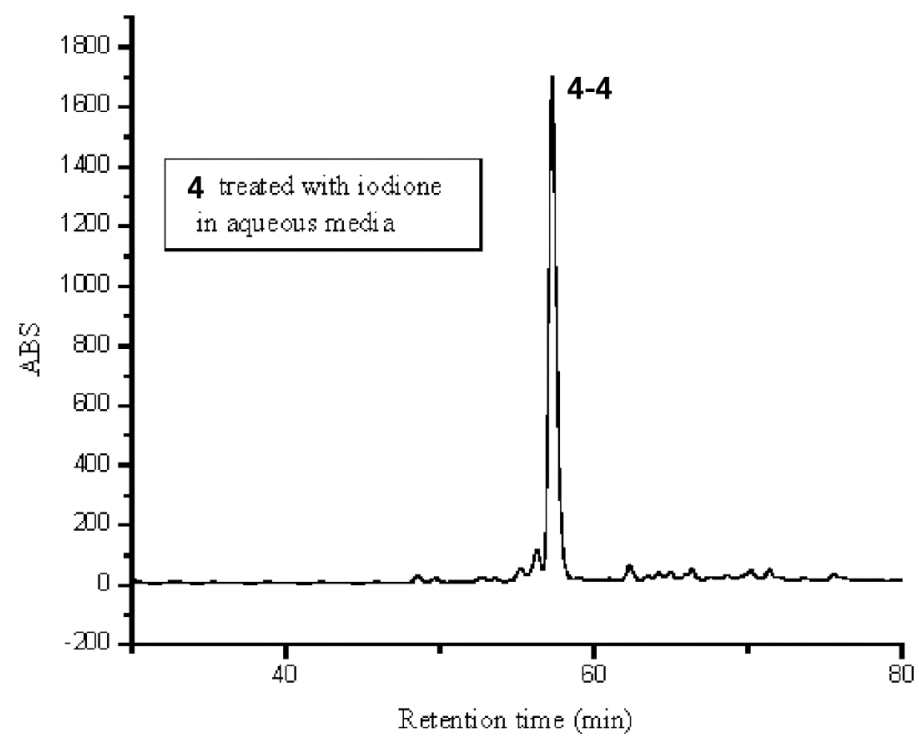

$57.30 \mathrm{~min}$, 4 self-dimer. 
II-3. The HPLC trace of the solution of 5 in $\mathrm{H}_{2} \mathrm{O} / \mathrm{THF}(9 / 1, \mathrm{v} / \mathrm{v})$ in the presence of iodine.

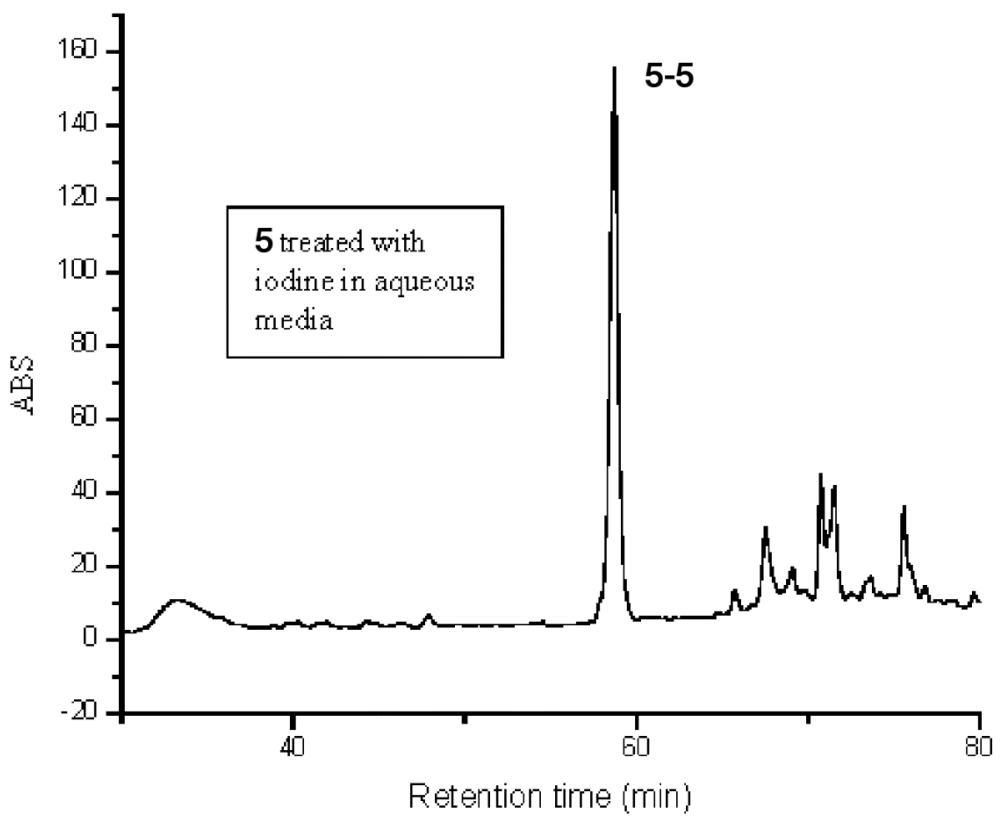

II-4. The HPLC trace of the solution of 6 in $\mathrm{H}_{2} \mathrm{O} / \mathrm{THF}(9 / 1, \mathrm{v} / \mathrm{v})$ in the presence of iodine.

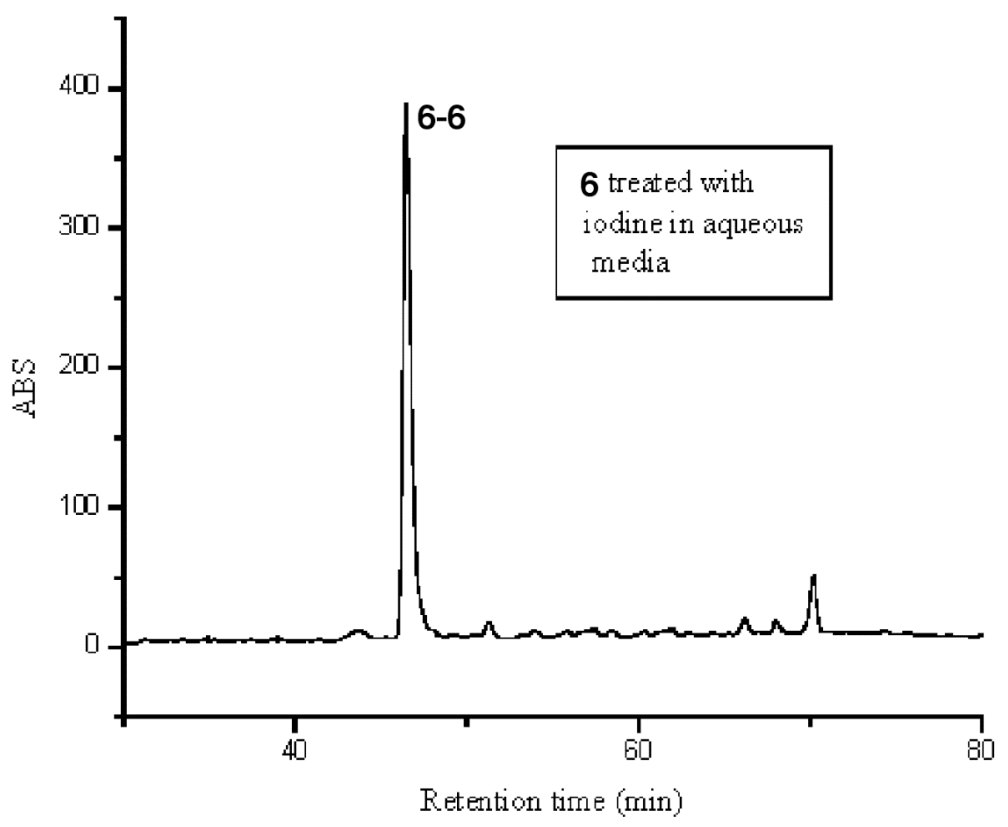

$i^{-} 46.47 \mathrm{~min}$, 6 self-dimer. 
II-5. The HPLC trace of the 1:1 mixture of 5 and $\mathbf{6}$ in $\mathrm{CH}_{2} \mathrm{Cl}_{2}$ in the presence of iodine.

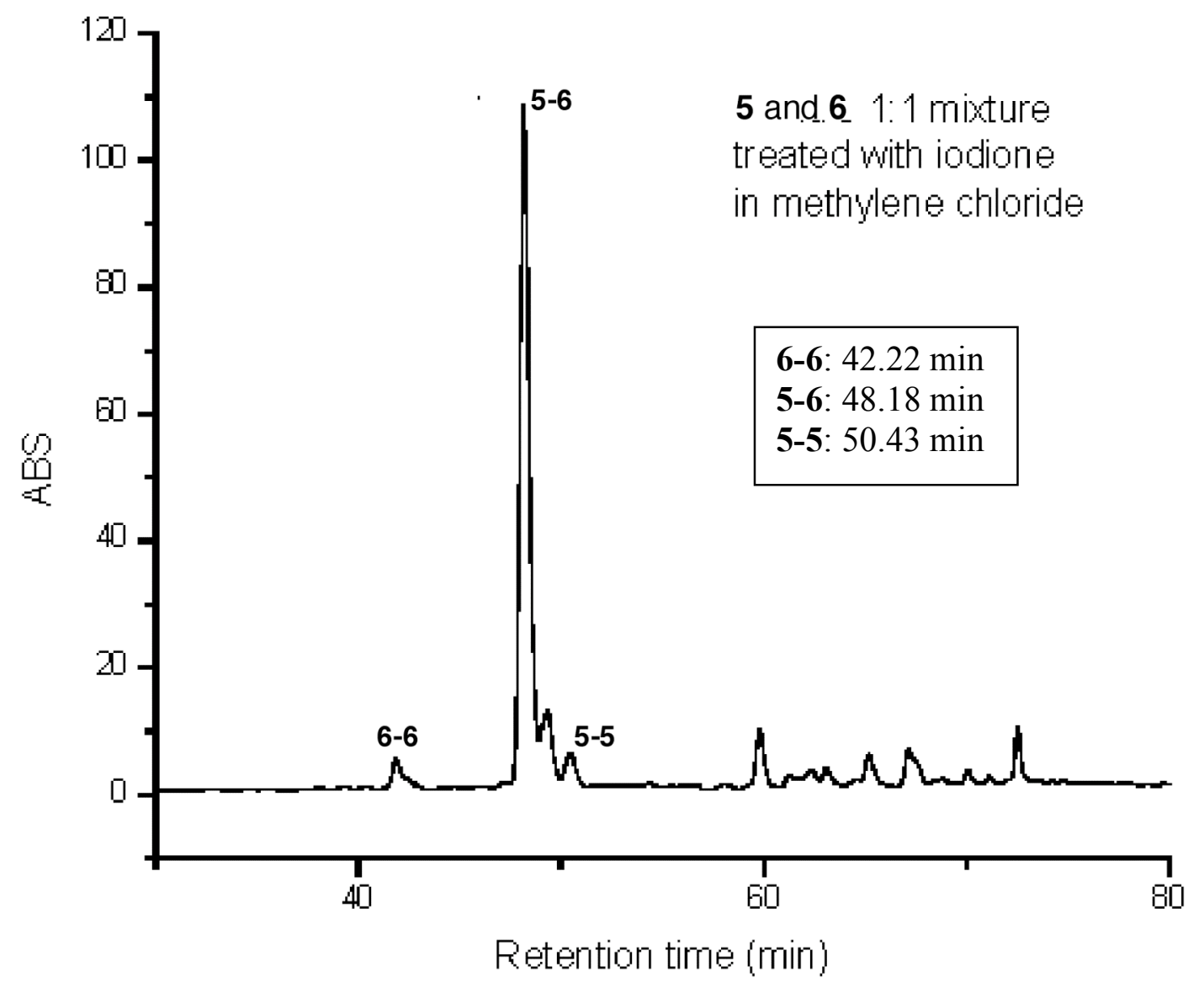




\section{Two-Dimensional NMR Spectra}

III-1. Partial 2D (NOESY) ${ }^{1} \mathrm{H}$ NMR spectrum of 5-6 in $\mathrm{H}_{2} \mathrm{O} / \mathrm{THF}-d_{8}(20 / 80$, v/v). (500 $\mathrm{MHz}, 278 \mathrm{~K}$, mixing time: $0.3 \mathrm{~s})$.

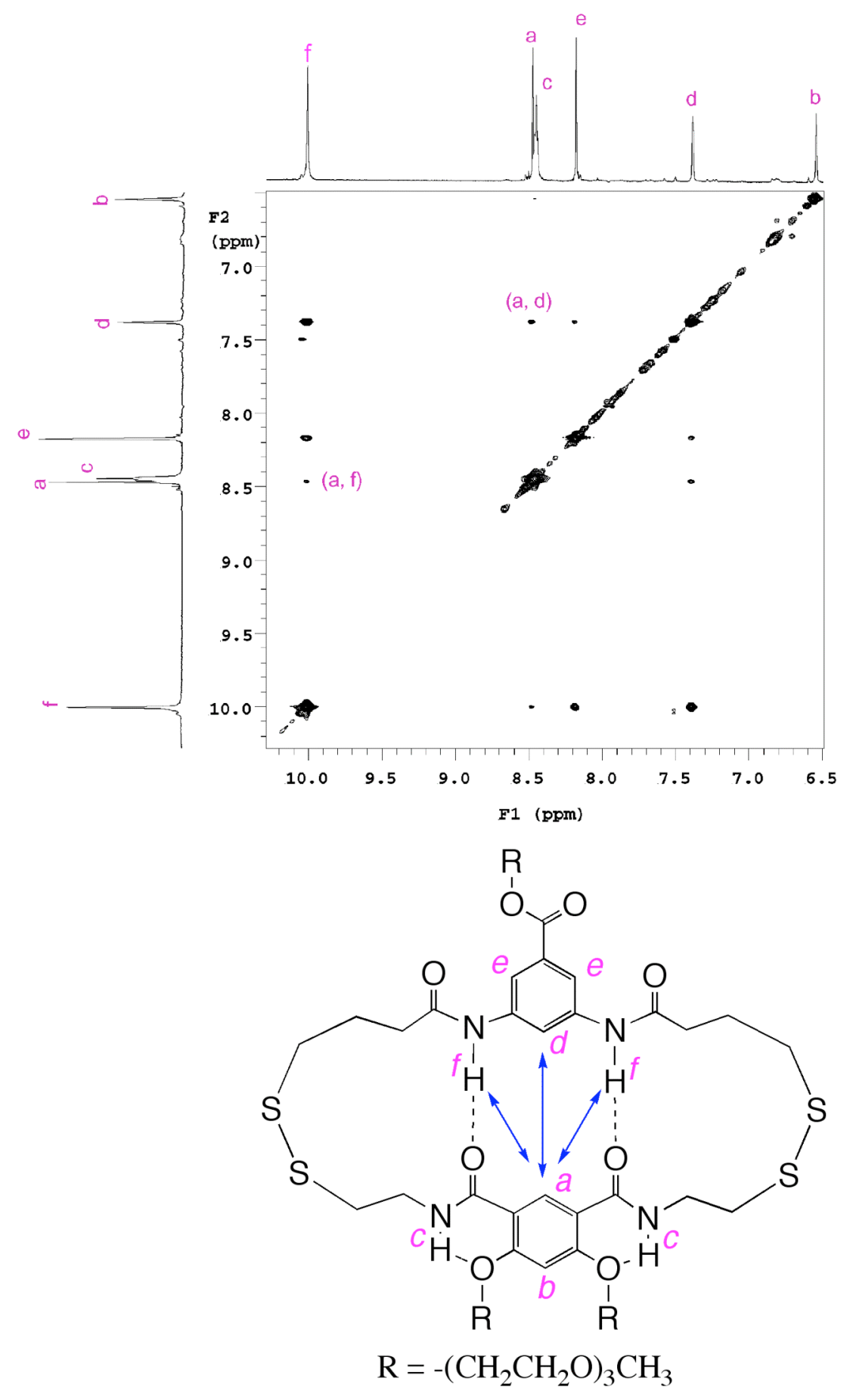


III-2. Partial 2D (NOESY) ${ }^{1} \mathrm{H}$ NMR spectrum of 5-6 in $\mathrm{H}_{2} \mathrm{O} / \mathrm{THF}-d_{8}(20 / 80$, v/v). (500 $\mathrm{MHz}, 278 \mathrm{~K}$, mixing time: $0.3 \mathrm{~s})$.

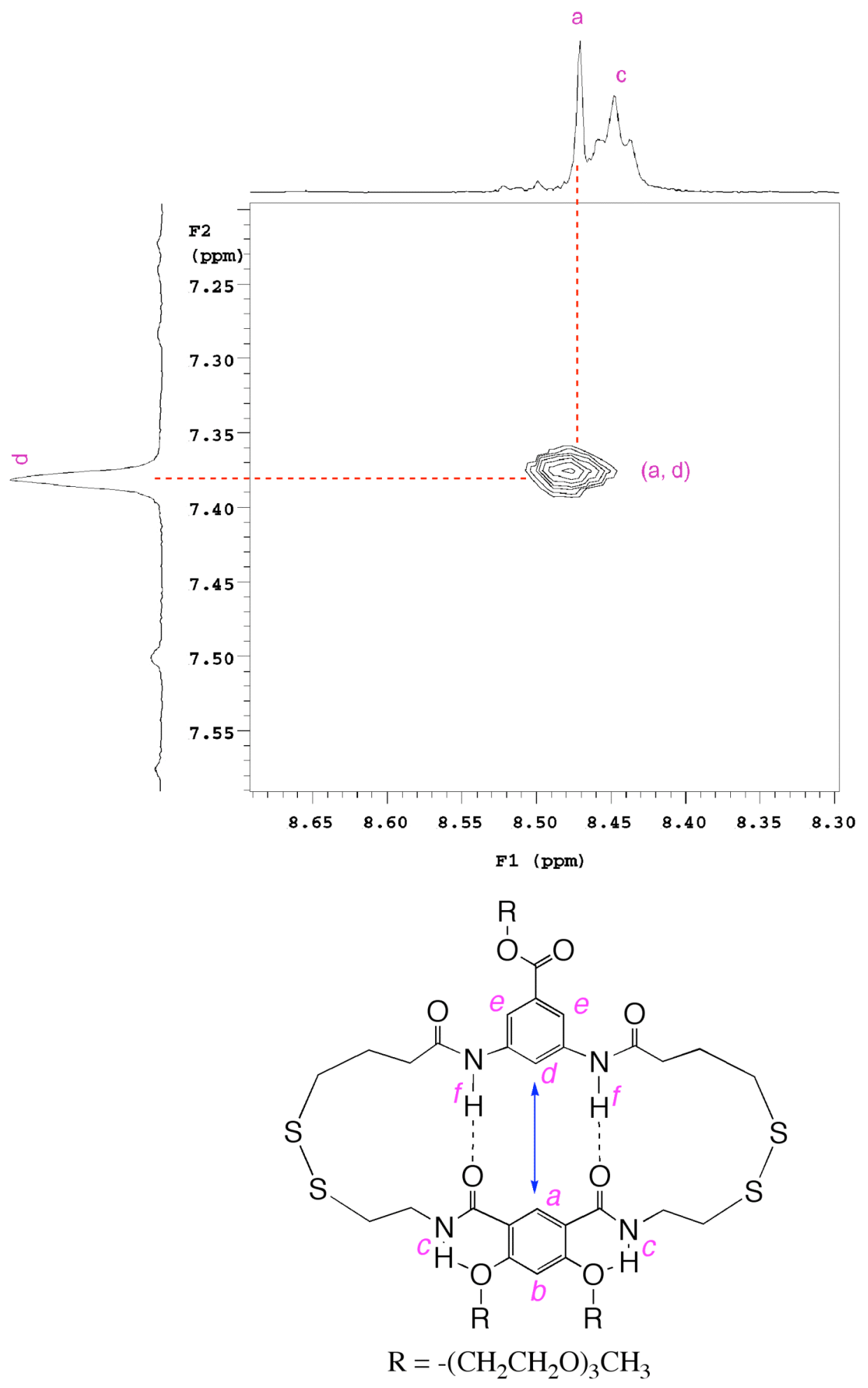


III-3. Partial 2D (NOESY) ${ }^{1} \mathrm{H}$ NMR spectrum of 5-6 in $\mathrm{H}_{2} \mathrm{O} / \mathrm{THF}-d_{8}(20 / 80$, v/v). (500 MHz, 278K, mixing time: $0.3 \mathrm{~s}$ ).
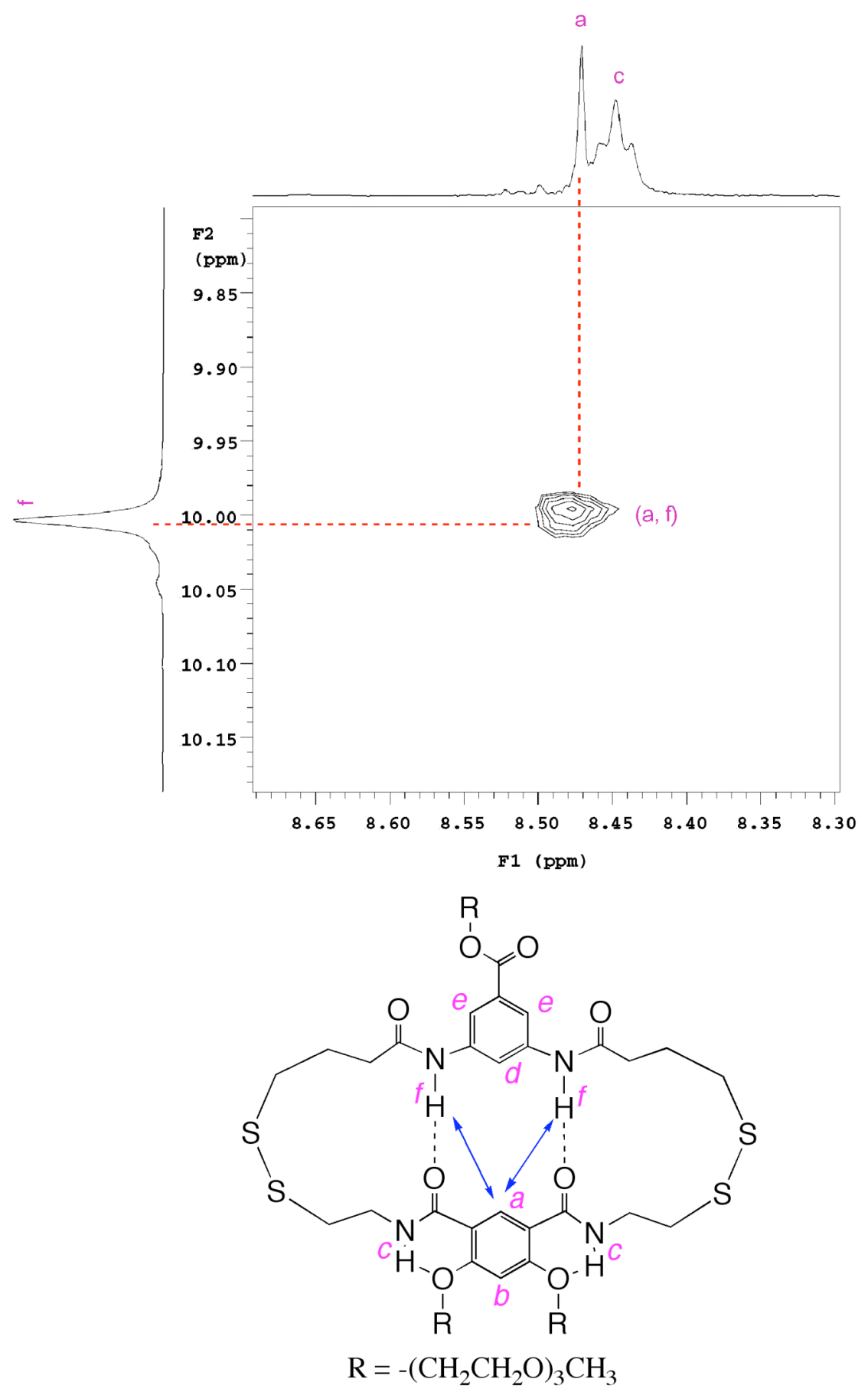
III-4. Partial 2D (ROESY) ${ }^{1} \mathrm{H}$ NMR spectrum of 5-6 in $\mathrm{CDCl}_{3}(500 \mathrm{MHz}, 278 \mathrm{~K}$, mixing time: $0.3 \mathrm{~s})$.

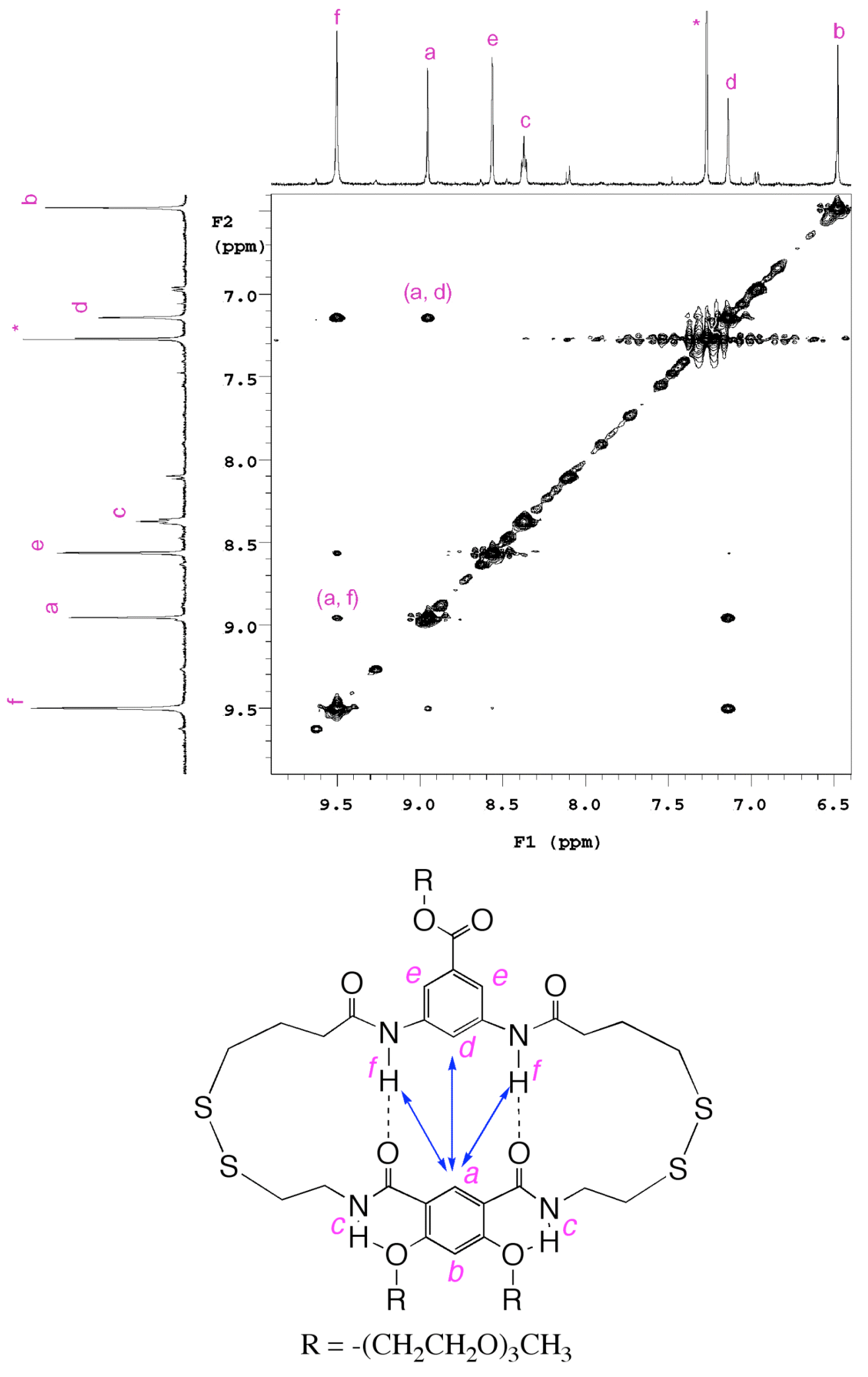


III-5. Partial 2D (ROESY) ${ }^{1} \mathrm{H}$ NMR spectrum of $\mathbf{5 \bullet 6}$ in $\mathrm{CDCl}_{3}$ (500 MHz, 278K, mixing time: $0.3 \mathrm{~s}$ ).

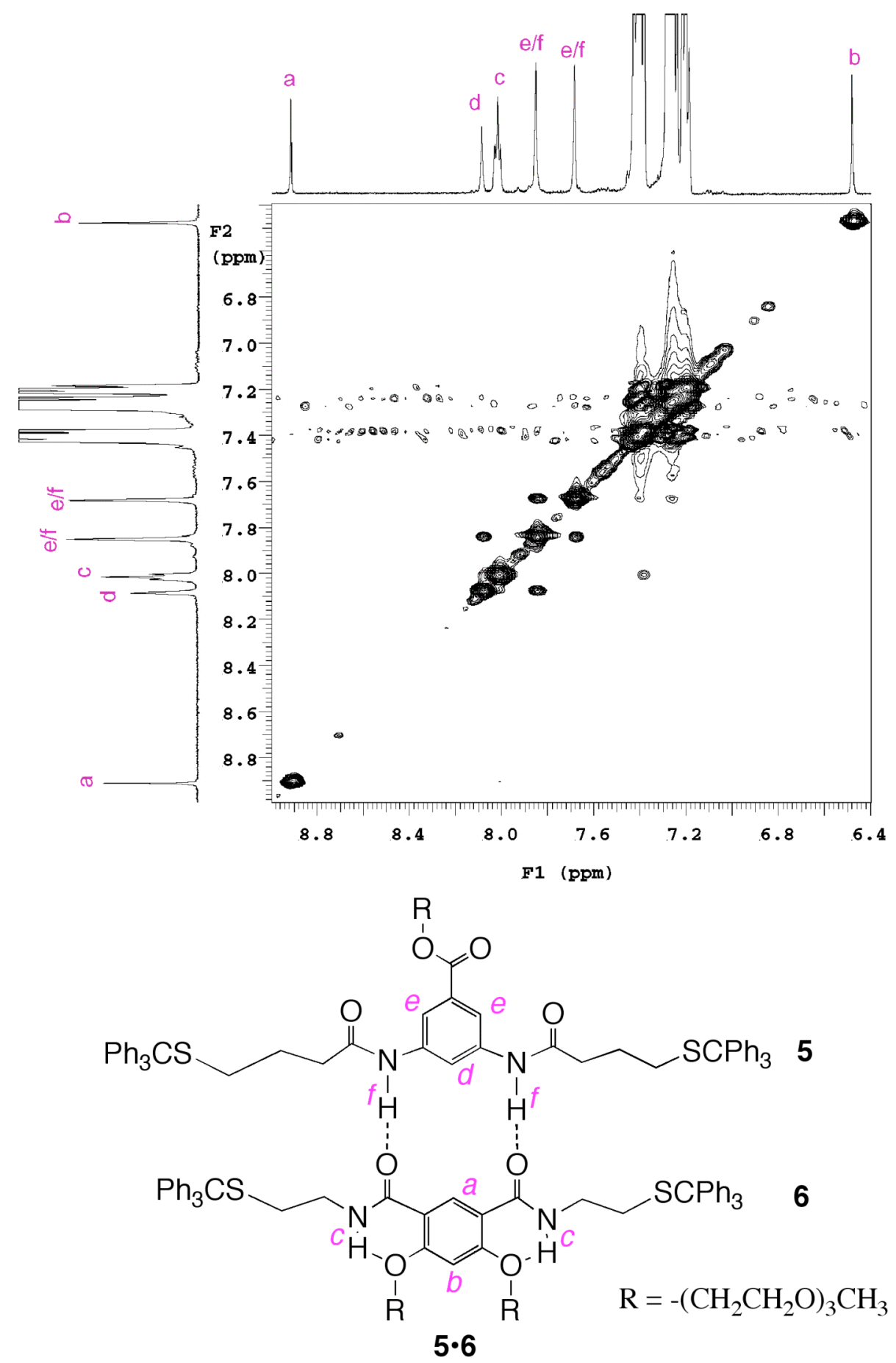

No NOEs (ROEs) can be detected between the protons of $\mathbf{5}$ and those of $\mathbf{6}$. 
III-6. Partial 2D (ROESY) ${ }^{1} \mathrm{H}$ NMR spectrum of $\mathbf{5} \bullet \mathbf{6}$ in $\mathrm{CDCl}_{3}$ (500 MHz, 278K, mixing time: $0.3 \mathrm{~s}$ ).
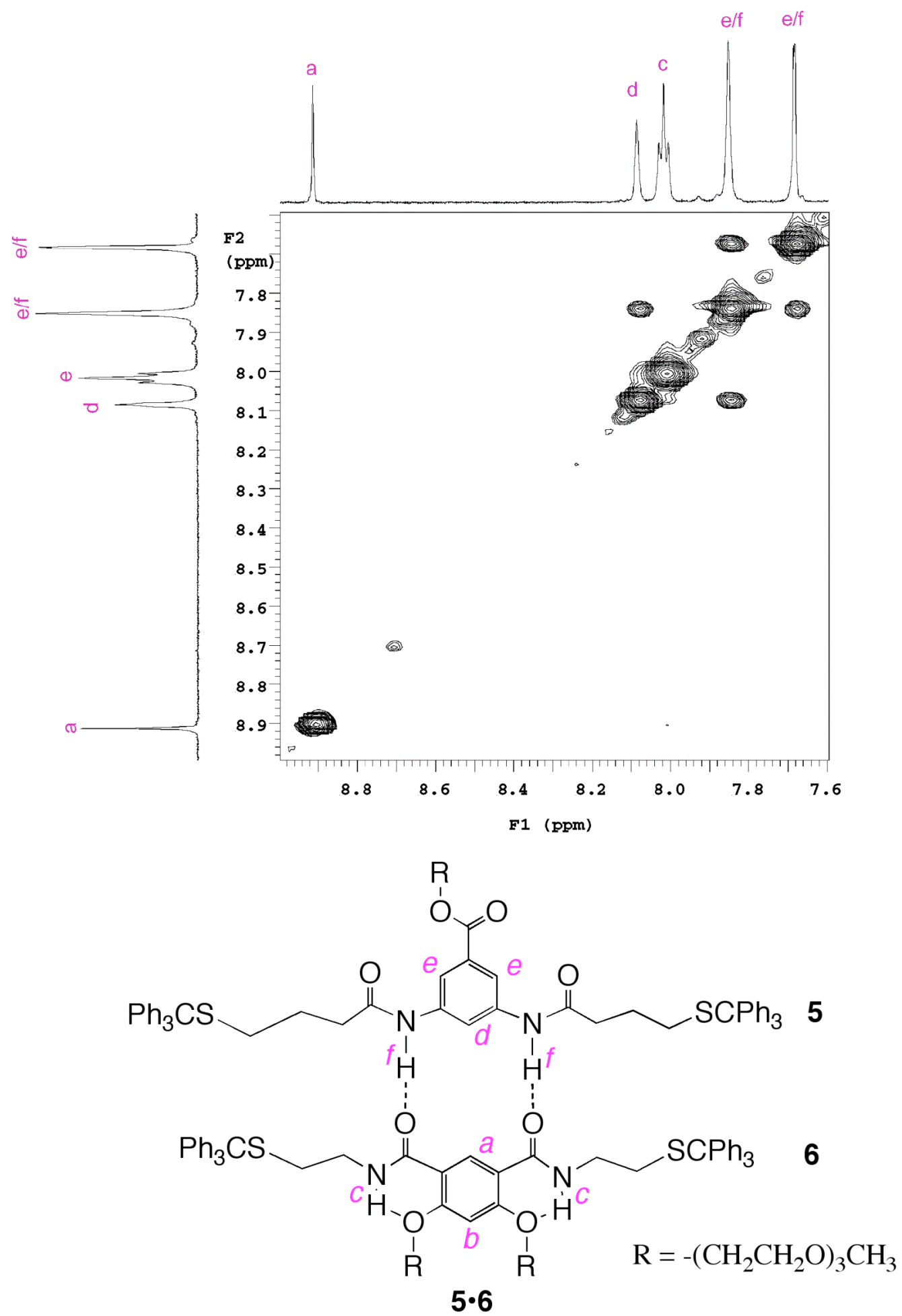

No NOEs (ROEs) can be detected between the protons of $\mathbf{5}$ and those of $\mathbf{6}$. 